\title{
Recurrent Angina Due to Epicardial Coronary Artery Spasm After Successful Bioresorbable Vascular Scaffold Implantation
}

Hannes Lindemann, MD; Udo Sechtem, MD; Peter Ong, MD

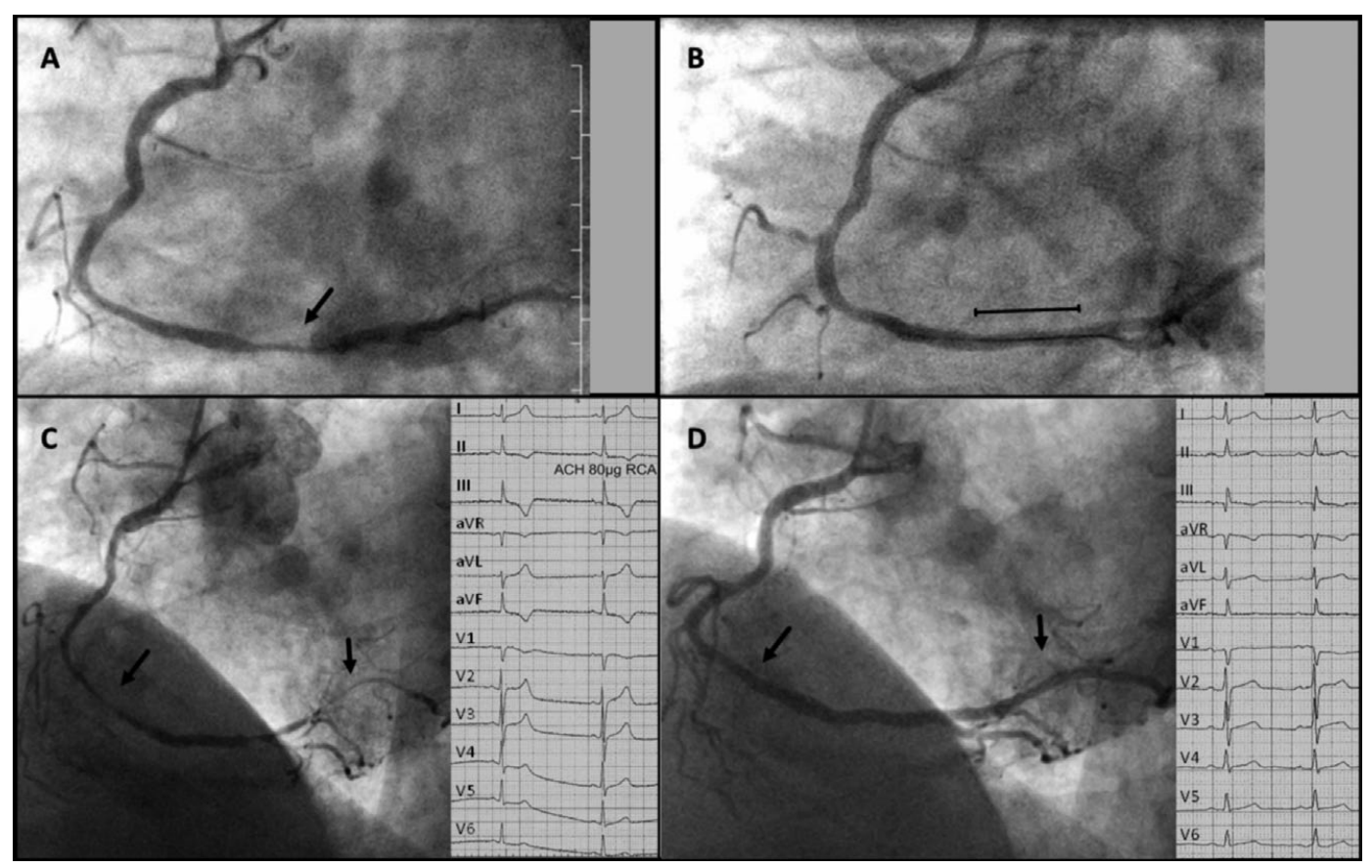

Figure 1. (A) Right coronary artery (RCA) at initial presentation at an external hospital 5 months previously (arrow, stenosis in the horizontal segment before the crux cordis). (B) RCA after successful implantation of bioresorbable vascular scaffold (BVS; marker). (C) RCA 5 months after BVS implantation after i.c. injection of $80 \mu \mathrm{g}$ acetylcholine (ACH). Black arrows, focal vasospasm proximal to the BVS and diffuse spasm distal to the BVS. Electrocardiogram (ECG) showed ST-segment depression in leads II, III, aVF, and the patient had reproduction of his symptoms. (D) RCA after i.c. injection of nitroglycerine $(0.2 \mathrm{mg})$. The symptoms, ischemic ECG changes and epicardial spasm resolved quickly.

B ioresorbable vascular scaffolds (BVS) have been proposed as an alternative therapy to bare metal or drugeluting metal stents for the treatment of epicardial coronary stenosis. Studies have suggested that BVS are able to restore vascular function in response to acetylcholine, ${ }^{1}$ but large-scale randomized data regarding the effects of this treatment on vascular function as compared with current thirdgeneration stents are still lacking. We recently showed that recurrent or ongoing angina after successful percutaneous coronary intervention (PCI) with metal stents in the absence of any relevant re-stenosis may be caused by functional coronary abnormalities. ${ }^{2}$ In the present study we describe the case of a patient with previous successful BVS implantation who was referred for repeated coronary angiography due to recurrent angina and subsequently underwent i.c. provocation testing with acetylcholine to identify coronary artery spasm.

Received March 12, 2015; revised manuscript received April 8, 2015; accepted April 12, 2015; released online May 7, 2015 Time for primary review: 4 days

Department of Cardiology, Robert Bosch Krankenhaus, Stuttgart, Germany

Mailing address: Peter Ong, MD, Department of Cardiology, Robert-Bosch-Krankenhaus, Auerbachstraße 110, 70376 Stuttgart, Germany. E-mail: peter.ong@rbk.de

ISSN-1346-9843 doi:10.1253/circj.CJ-15-0279

All rights are reserved to the Japanese Circulation Society. For permissions, please e-mail: cj@j-circ.or.jp 


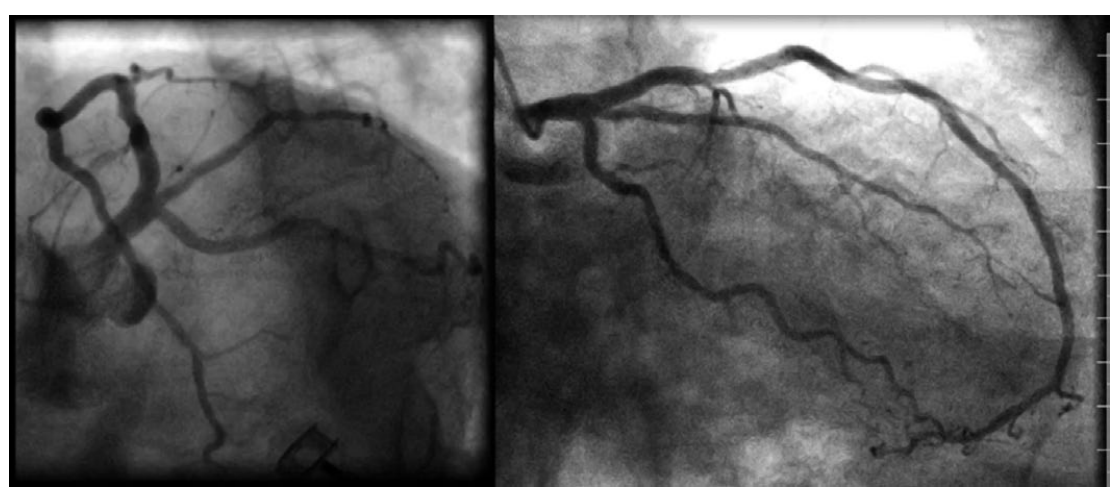

Figure 2. Coronary angiography of the left coronary artery in (Left) left anterior oblique and (Right) right anterior oblique views showing no relevant epicardial stenosis.

A 59-year-old man had been treated at an external hospital for angina pectoris under exertion as well as at rest, especially during periods of emotional stress. The patient's cardiovascular risk factors included arterial hypertension, hypercholesterolemia, being a former smoker (40 pack years); and myocardial infarction in his father at the age of 55. During coronary angiography a stenosis in the right coronary artery (RCA) was noted and a BVS (Absorb $3.0 \times 18 \mathrm{~mm}$; Abbott Vascular) had been implanted (Figures 1A,B). Before the BVS implantation the patient had been taking the following medications: lisinopril $20 \mathrm{mg}$ once daily, bisoprolol $5 \mathrm{mg}$ once daily. After BVS implantation he was discharged with the same medication, and also aspirin $100 \mathrm{mg}$ once daily and ticagrelor $90 \mathrm{mg}$ twice daily. The patient was referred to our hospital 5 months later with symptoms compatible with acute coronary syndrome (ie, chest pain at rest $>20 \mathrm{~min}$ ). These symptoms had occurred several times before with spontaneous resolution. Of note, $0.4 \mathrm{mg}$ sublingual nitroglycerin was very effective in relieving his symptoms. Twelve-lead resting electrocardiogram (ECG) and the laboratory findings did not show acute myocardial ischemia or necrosis. Due to suspected progressing coronary artery disease, a diagnostic coronary angiogram was performed, which showed no relevant epicardial stenosis nor in-scaffold restenosis (Figures 1D,2). To further elucidate the origin of the symptoms, i.c. acetylcholine provocation testing was performed as described previously. ${ }^{3,4}$ The test did not indicate any spasm in the LCA. Thus, the RCA was challenged with $80 \mu \mathrm{g}$ acetylcholine. During the test in the RCA the patient had the same chest pain that he had had several times at home at rest. ECG showed deep ST-depressions in leads II, III, aVF and the angiogram showed a focal, nearly occlusive vasospasm in the mid-RCA, in the segment proximal to the site of the previously implanted BVS. Furthermore a diffuse spasm in all segments distal to the BVS was seen (Figure 1C). The site of the BVS did not show any relevant vasoconstriction. After i.c. nitroglycerine injection the changes quickly resolved (Figure 1D).

This case illustrates that despite successful BVS implantation, epicardial coronary artery spasm may represent an important cause of recurrent angina after PCI. Given that no functional coronary vasomotor assessment had been performed prior to the BVS implantation it can only be speculated whether the RCA spasm was already present beforehand or had been triggered by it. The fact that the symptoms before PCI consisted of both exertional and resting angina, does not exclude the possibility that coronary spasm existed before BVS implantation because coronary spasm may also be triggered by exercise. ${ }^{5,6} \mathrm{It}$ is also conceivable, however, that the BVS implantation led to an alteration of vascular communication and subsequent spasm. ${ }^{7}$ Although spasm after successful PCI is often seen distal to the site of PCI, factors such as direct toxic effect from the entrapped drug or hypersensitivity to the polymer of the stent or the drug may have contributed to the enhanced vasoconstriction proximal and distal to the site of PCI.

I.c. spasm provocation testing in these patients may be useful to detect the underlying mechanism for the clinical presentation, institute appropriate medical therapy with calcium channel blockers and nitrates and avoid further unnecessary invasive re-assessments. Further pre- and post-interventional studies are needed to understand how the tendency to spasm is influenced by PCI.

\section{Disclosures}

No conflicts to disclose.

\section{References}

1. Serruys PW, Ormiston JA, Onuma Y, Regar E, Gonzalo N, GarciaGarcia HM, et al. A bioabsorbable everolimus-eluting coronary stent system (ABSORB): 2-year outcomes and results from multiple imaging methods. Lancet 2009; 373: 897-910.

2. Ong P, Athanasiadis A, Perne A, Mahrholdt H, Schäufele T, Hill S, et al. Coronary vasomotor abnormalities in patients with stable angina after successful stent implantation but without in-stent restenosis. Clin Res Cardiol 2014; 103: 11-19.

3. Lüscher TF, Pieper M, Tendera M, Vrolix M, Rutsch W, van den Branden $F$, et al. A randomized placebo-controlled study on the effect of nifedipine on coronary endothelial function and plaque formation in patients with coronary artery disease: The ENCORE II study. Eur Heart J 2009; 30: 1590-1597.

4. JCS Joint Working Group. Guidelines for diagnosis and treatment of patients with vasospastic angina (coronary spastic angina) (JCS 2013): Digest version. Circ J 2014; 78: 2779-2801.

5. Yasue H, Omote S, Takizawa A, Nagao M, Miwa K, Tanaka S. Circadian variation of exercise capacity in patients with Prinzmetal's variant angina: Role of exercise-induced coronary arterial spasm. Circulation 1979; 59: 938-948.

6. Kawana A, Takahashi J, Takagi Y, Yasuda S, Sakata Y, Tsunoda R, et al. Gender differences in the clinical characteristics and outcomes of patients with vasospastic angina: A report from the Japanese Coronary Spasm Association. Circ J 2013; 77: 1267-1274.

7. Tran $\mathrm{CH}$, Welsh DG. The differential hypothesis: A provocative rationalization of the conducted vasomotor response. Microcirculation 2010; 17: 226-236. 